Becci A. Akin \& Thomas K. Gregoire

\section{ABSTRACT}

The helping system often responds to parents recovering from addiction in a way that reinforces their powerlessness and may perpetuate their addiction. This study identified worker and agency qualities that contribute to parents' recovery and family reunification. The authors conducted a qualitattve study of successful clients of the child welfare system who regained their children after recovering from addiction. These parents describe the importance of workers' understanding the context of addiction from the parent's perspective.

Becd A. Akin is research assistant, School of Soclal Welfare, University of Kansas, Lawrence, Kansas. Thomas K. Gregolre is assistant professor, college of Sodal Work, Ohlo State University, Columbus, Ohlo. This article is based on work funded by $a$ grant from the Kansas Social and Rehabilltation Services, Ttte $N-E$, Short-Term Tralning.

\title{
Parents' Views on Child Welfare's Response to Addiction
}

$\mathrm{C}$ hild-maltreatment incident reports increased by $50 \%$ between 1988 and 1993, totaling more than 2.9 million reports in 1993 (McCurdy \& Daro, 1994). Much of this increase can be attributed to substance abuse (Curtis \& McCullough, 1993; General Accounting Office, 1994; McCurdy \& Daro, 1994; Tatara, 1989-1990). The National Committee to Prevent Child Abuse's recent survey of public child welfare agencies indicates that as many as $80 \%$ of child-maltreatment cases are associated with alcohol and other drug problems (McCurdy \& Daro, 1994). Moreover, substance abuse often inhibits the system's ability to meet the goal of preserving families. Children from substance-abusing families are more likely to remain in care longer and to experience multiple placements and are less likely to be reunited with their biological families (Besharov, 1990; Fanshel, 1975; Feig, 1990; Regan, Ehrlich, \& Finnegan, 1987;
Thompson, 1990; Walker, Zangrillo, \& Smith, 1991). As the number of chemically dependent families entering the child welfare system increases, the field must find more effective responses to alcohol and drug abuse.

The Adoption Assistance and Child Welfare Act of 1980 (PL 96272) mandates the child welfare system to make "reasonable efforts" at keeping children and families together. Despite the growing influence of substance abuse, several studies suggest that many social workers are either ill prepared or unwilling to respond to this problem (Googins, 1984; Gregoire, 1994; Kagle, 1987; King, Bissell, \& O'Brien, 1979; King \& Lorenson, 1989; Morehouse, 1978; Peyton, 1980; Thompson, 1990; Van Wormer, 1987).

In that alcohol and drug abuse is often perceived erroneously as a morally wrong, willful behavior, a common response is to punish parents (Rhodes \& Johnson, 1994). Current policies

Families in Society: The Journal of Contemporary Human Services Copyright 1997 Families International, Inc. 
that criminalize pregnant women for their addiction exemplify this reaction to alcohol and drug abuse (Gustavsson, 1991). However, punitive attitudes toward addiction only fuel stigmatization for families and inhibit help-seeking behavior (Finkelstein, 1994).

Professional avoidance represents a second characteristic response to addiction. Even when substance-abuse problems are identified, social workers frequently ignore or compartmentalize them as a separate life issue (Kagle, 1987). Some social workers subscribe to the notion that individuals must "hit bottom" before being helped. Others disregard the potential for change because of faulty beliefs that persons with substance-abuse problems cannot get well. These erroneous beliefs prevent helpers from recognizing the potential of early identification and intervention (Googins, 1984; King \& Lorenson, 1989; Pilat \& Jones, 1985).

Although the literature has documented the problems associated with the child welfare response to addiction, few descriptions of parent and agency success in responding to the problem are available. Despite the ineffective responses of the helping system, some persons do get well. Much can be learned from these successful parents. This article describes the results of a qualitative study consisting of individual interviews with parents who have recovered from addiction and regained their children. We rely on the expertise of successful clients to describe both impediments and contributors to effective recovery and family reunification in order to learn from the voice of experience.

\section{Methodology}

\section{Research Question}

The study proposed to increase worker's ability to understand and respond to clients with addiction problems. Believing that these parents possess significant knowledge about what has worked for them, we used client expertise to evaluate services. We explored the experiences and perceptions of parents involved with the public child welfare system by asking two primary questions: (a) How do parents experience addiction? (b) What characteristics of the child welfare system do parents identify as assisting or inhibiting their family reunification and recovery?

\section{Sample}

The sample of parents was a purposeful sample of extreme cases (Lincoln \& Guba, 1985). We sought to learn from parents who had successfully addressed their addiction problem.

Participants were recruited through the state child welfare agency and private, nonprofit agencies. Social workers were asked to identify past and current clients who met the following requirements.

- The parent had been involved with the public child welfare system for reasons of child abuse or neglect.

- The parent was identified as having problems associated with alcohol or other drugs.

- The parent self-reported that he or she was currently abstaining from alcohol and illicit drug use.

- The parent had or was currently in the process of regaining custody of his or her children.
Parents were initially contacted by their worker. Upon agreeing to participate, the researcher scheduled a meeting. Of those parents contacted, only one refused to participate. This parent stated that she was afraid of retribution if she were to express negative opinions about the state agency.

Participants represented both rural and urban areas of the state, ranged in age from their early twenties to mid-thirties, and had an average of three children. Six of the women were White and five were African American. Cocaine (or crack) was reported as the primary addictive drug for eight of the parents, alcohol for two parents, and methamphetamine for one parent.

\section{Data Collection}

Data were collected through individual interviews. Interviews were a particularly useful method for this study because they permitted access to people's ideas, opinions, and thoughts in their own words (Reinharz, 1992). In this way, learning from clients was given prominence and priority.

The first author conducted interviews using a semistructured format. Broad, open-ended questions were asked at the beginning of the interview; more specific questions followed to assure that a core set of topics was covered with every participant. In an attempt to ensure consistency among the inquiries, this core set of questions did not change during the course of the study, even when findings suggested a topic was unimportant to the participants. For example, although participants consistently undervalued the role of specific social services, they were nevertheless 
Table 1. Preliminary themes.

Parental perceptions of authority/power

Relationship as primary to helping

Client versus worker perspectives

Workers lack of knowledge and avoidance of addiction

Importance of worker expectations

asked a question to elicit their opinions about the services they found most helpful.

The length of the interview ranged from one to two and a half hours. Participants were given the choice of meeting in their homes or the agency office; all but one participant chose their home. Informal member checking (Lincoln \& Guba, 1985), such as paraphrasing, was used to clarify and assure that appropriate interpretations were made. Formal member checking was used by telephoning several participants for their feedback on preliminary analyses.

Data collection also included recording logs and journals. Immediately after each interview, the interviewer audiotaped initial impressions of what appeared to be significant points. Within one to two days following the interview, notes were written about key themes, new questions, and contradictions that surfaced in the data. This $\log$ served as a primer for upcoming interviews. A third journal recorded the researcher's comparisons among the interviews and common ideas that continued to reappear.

\section{Data Analysis}

Constant comparative analysis was the primary method of data analysis (Lincoln \& Guba, 1985). With this method, data analysis is an integral part of the entire research process and begins immedi-
Diorio, 1992

Magura, 1982

Maluccio, 1979a, 1979b; Giordano, 1977

Googins, 1984; King \& Lorenson, 1989; Van Wormer, 1987

Leake \& King, 1977

ately following the first data-collection activities. The process began with a list of tentative themes based on the literature review (Table 1). However, new themes emerged as participants provided their own ideas and insights. Consistent with the concept of grounded theory (Lincoln \& Guba, 1985), original themes were changed or omitted as data revealed new and different perspectives.

Constant comparative analysis is a complex and detailed process that requires the researcher continually to double back in data coding (Bogdan \& Biklen, 1982). All interviews were audiotaped and fully transcribed. Coding categories were developed to analyze transcriptions. The beginning list of coding categories was significantly refined during data collection and analysis. Categories were changed, omitted, reshaped, and integrated into other categories as warranted by the data. New themes were constantly compared with previous ones. This crisscross exercise resulted in comparing each interview with data from all other interviews.

\section{Findings}

Organized around three primary themes, Table 2 displays the themes derived from parent inter- views. These findings summarize 11 parents' opinions about what worked for them in achieving recovery and family reunification.

\section{The Addiction Experience}

Many clients perceive that social workers whose lives have not been touched by chemical dependency do not comprehend the impact of this experience upon the addicted persons and their families. The first theme uses the parents' words to explain the addiction experience. Addiction has been defined as "a behavior pattern of compulsive drug use characterized by overwhelming involvement ... with the use of a drug and the securing of the supply, as well as a tendency to relapse after completion of withdrawal" (Bratter \& Forrest, 1985, p. 250). Although technical definitions of substance abuse provide relevant information about the nature and progression of addiction, they fail to divulge its emotional and spiritual meaning for those who live with it. Workers cannot be effective without knowing how addiction shapes and transforms the family.

Table 2. Prevalence of themes of addiction and recovery.

\begin{tabular}{lr}
\hline Theme & $n$ \\
\hline Addiction experience & \\
Addiction is omnipresent & 11 \\
Usurps personal power & 11 \\
The quit conflict & 11 \\
System shortcomings & \\
Reinforcing powerlessness & 10 \\
No one cares & 10 \\
Unrealistic expectations & 10 \\
System successes & \\
Building relationships & 11 \\
Sharing power & 11 \\
Providing direction & 9 \\
Know addiction & 10
\end{tabular}


Addiction is omnipresent. Parents in this study understood addiction from an affective point of view; their definitions came from their gut not their head. Though they offered various analogies for addiction, they all expressed a common theme that viewed addiction as an omnipotent, omnipresent force. Their relationship with drugs was the most powerful relationship they had experienced. Accordingly, they referred to alcohol and drugs as a god, a best friend, and as the center of their lives.

When asked to describe addiction to someone who is foreign to the concept, participant $\mathrm{G}$ said that it was "like the Pepsi slogan-you gotta have it." This idea was echoed by participant $F$ who answered the same questions with the reply:

You'll do anything for it.... At no cost, with no thought to consequences. You just don't care about anything but that. It consumes all of your thinking. That's a good one. It just takes over your whole thinking ... your actions, everything.

Their addiction consumed their lives. Parents organized their daily activities around the use of alcohol or drugs. Cocaine-addicted parents described it as an incredible chase. Participant F said:

\section{Cocaine just tells you, "Do more!" With crack, there is no such thing as just say no. There really isn't... You can't go, "Hey, no, no thanks. I don't do drugs. "It's not like that. Not with cocaine.... If it's there, your body jumps. Your mind follows later... That's what that drug does. It tells you to do more.}

Parents described their relationship with chemicals as being characterized by tremendous hardship and struggle. The drug was si- multaneously their "best friend" and a "living hell." Paradoxically, they were "living for drugs" while "walking around in death." Despite the detrimental effects of alcohol and drug abuse, they continued to pursue their addiction. They described feelings of apathy, selfpunishment, and guilt; illogical and "crazy" thoughts; and a life marked by misery. Participant $C$ described the process of addiction as torture.

It was mental, physical, emotional
torture. But tt wasn't so much the
addiction that was torture for me as
it was... the whole process of the
addiction, everything that came
and played with the addiction...
And so it wasn't so much the addic-
tion as what the addiction will allow
you to do... the bying, the stealing,
the running around.

Participants felt shameful and guilty about their problems with addiction. In response to this emotional pain, they tried to explain their reasons for using alcohol and drugs. Several women described family history as a factor. These participants believed that growing up with addiction taught them to view abusive behavior as a normal part of family life. They avoided feelings, escaped reality, managed guilt, and punished themselves for mistakes.

With drugs as the major coping mechanism, clients described a downward spiral of unacceptable drug-induced behavior followed by remorse, guilt, and more drug use. While they used drugs and alcohol, they perceived themselves as unworthy of love and help from others. Participant B described her despair:

Addiction was like an 1-don't-care attitude. Figured I got to die from something... I didn't have no hope or nothln' Ilke that. I've been on my own, had my first chlld at 14, and after that I was on drugs... I sald I would never do it, but I did. I was staying on the streets, didn't have nowhere to go, and that's all I knew was to do drugs.

Addiction usurps personal power. Participants uniformly described a sense of powerlessness in the face of their addiction. Their relationship with drugs had diminished their personal power and their ability to exercise free will with respect to drug-using behavior and most other areas of their life:
Addiction is ... loss of power and life. Because drugs control your ufe, you don't And when you start doing drugs, you have no control over your lffe and nothing else around you. Yeah, it has the power. It takes your power and as long as cocaine has your power there is nothing else you can do In Iffe. You can't hold a job or work and take care of your kids. You can't take care of your- seff... Cocalne is the power.

My whole soul was tired... My mind didn't think anymore ... just like the cocaine had taken over my mind.

The quit conflict. From each interview, themes regarding how difficult it was to quit drugs or alcohol emerged. Participants discussed their fear of admitting that they had an addiction, believing that this would open them to other problems, especially the possibility of losing their children. Parents said they were unaware of services that would help them get off drugs and keep their families together. If they knew about treatment services, other obstacles prevented them from asking for help. Participant $K$ explained that asking for help would mean swallowing her pride and admitting her imperfections. 
I was always looked at as self-suffcient. I don't Ilke asking for help. It has always seemed like a weakness to me SRS, treatment, all of it has always seemed to me like a weakness. It's hard to ask for help. It's hard to admit I'm doing something wrong and not doing what I should be doing or I' $m$ not perfect... Asking for help, to me it would be like I wasn't being a good mother.

Parents described a tremendous desire to quit. They wanted to be off drugs; they were tired of the chase. However, the idea of life without drugs seemed desolate. Having relied on drugs as the primary means of coping and support, clients often took tentative steps toward help only to withdraw into their addiction. Participant $\mathrm{H}$ said:

\section{You want to quit, but you just don't know how. You don't know where to go. You figure that if you do quit that you're alone because that co- caine has been your support all your Iffe. And you wonder where you can go to get that support... You feel there is no hope. You want all the help in the world, but you are scared. It's like one minute you want it and then you go right back using.}

\section{System Shortcomings}

Parents in this study had successfully reshaped their lives by learning to live without drugs and alcohol. But their victories were hard fought, and the journey was not always easy.

Although some participants eventually developed strong and healthy relationships with child welfare workers, others described interactions that continued to be hurtful and difficult. These mothers felt shameful that their abuse of alcohol or drugs had harmed their children. They described a degraded sense of self-worth for being associated with the state wel- fare system. One parent explained, "It seems like I'm not as important because I'm on welfare." And another believed she was viewed as "inferior" to the worker because the worker had a job and she did not. Feelings of low self-worth were exacerbated by the system's lack of responsiveness. The following themes suggest that system practices that ignored the guilt, shame, and feelings of inferiority seriously inhibited recovery and family reunification.

\section{"}

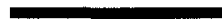

Although technical definitions of substance abuse provide relevant information about the nature and progression of addiction. they fail to divulge its emotional and spiritual meaning for those who

$$
\text { live with it." }
$$

Reinforcing powerlessness. Though parents experienced a range of emotions after learning that the state had entered their lives to investigate charges of child abuse and neglect, they consistently described their initial reaction as anger followed by sadness and powerlessness.

Parents discussed the loss of their children with intense sadness and grief. Losing her children to the state was described by participant $\mathrm{H}$ as akin to being thrown in prison: "It was like back behind bars again." Participant D compared the removal of her children to death:

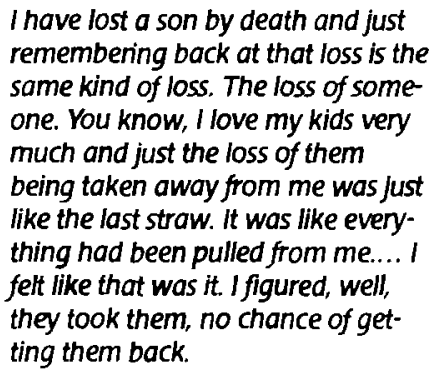

I have lost $a$ son by death and just remembering back at that loss is the same kind of loss. The loss of someone. You know, I love my kids very much and just the loss of them being taken away from me was just like the last straw. It was like everything had been pulled from me.... I felt like that was it. I figured, well, they took them, no chance of getting them back.

When G's two children were removed, she "felt like, why cry? ... I lost all my hope." Similarly, participant $F$ described the loss as a death and felt there was nothing left to do.

\section{I wrote a poem, "The Empty Crib," and people that read it cry.... I don't think l ever cried so hard in my entire life. I remember that ay being all night long and my hus- band hold 'n' and holdin' me. It was like they had died. I felt like they had died. I couldn't believe that I could let this happen. We just kept saying to each other, how could we have let this happen? 'Cause you know, how the drugs have wom off now and it was horible. I remem- ber thinking I'l never get clean and sober, so I'll never get them back.}

Feelings of hopelessness were compounded by a sense of powerlessness. Parents repeatedly painted a picture of the state as all powerful and of themselves as helpless. They used these words to describe the experience: threats, fear, scared, and desperate. Participant E said, "They got the power. They controls your life.... They have the power to do anything they want 'cause theys gots your kids. I ain't got no power over me. I'm powerless."

Participant $\mathrm{C}$ explained how hopelessness and powerlessness were a recipe for inaction. 
It's almost Iike, yeah, you'll give up. I mean, it's like, I am not going to keep on. They already have my child. In other words, you have everything I have. O.K., what more can you take? I'm trying to do what I can. Maybe I can't do it the way that you want me to but I am constantly trying. And, yes, maybe I make two steps forward and one back or even maybe one forward and two back. But at least I am making some effort to get my child. And then you have this person-well you're not doing enough... I sit here and think. Before Ilet you break me, I'll give up.

Participant D explained that her powerlessness prolonged her not seeking help:

It was like there was nothing / could do 'cause you feel like you got your hands tied. Although you got parental rights, you stlll feel like you have your hands tied with the state. You know, they don't give you no choices. That's a lot of it. I didn't feel like I had any choice. I stayed out drunk for another year and $a$ half. in and out of the program, because they were threatening to aut my rights. I was like, Shitl They want me to do all this other stuff and I have done and done and done. Done what they ask me to do and still they aren't holding up their end of the bargain. I just got to a point where I just said, "Screw it, I don't want it." I was about ready to say, You want my kids, take them! You want to keep them away from me so bad, take 'em."

Feelings of fear and powerlessness were not immediately eliminated even when their children were returned. Participant $\mathrm{H}$ said, "I'm living a perfectly clean life now, but I'm still in that fear. That fear that they will just come take my child if they feel like it." Removal of their children left parents with a deep emotional scar not easily healed.

No one cares. Parents often perceived the system as unsupport-

ive and uncaring. When participant $D$ was asked what the state agency did to help her, she responded,

\begin{abstract}
Nothing/ They were more Interested in just threatening me to aut my nights. That's it.... You were lost in the system. Here's these kids, you know, and you are doing everything you are supposed to do. The case is lost. I mean, half the time she couldn't even find the records or the fle or anything. It was very emotional and would tear you up emotionally. Because it's I/ke, don't you even care? Don't these people care that these kids, that people are trying to get 'em back?
\end{abstract}

Other participants reiterated this position by describing the system as "more concerned about paperwork" than families. Participant H said,
I always thought that a social work- er was supposed to be your buddy, your pol, gonna help you and your kids get somewhere. You have more of them that could give a damn. All they want to do is make sure your paperwork is in there... If you got $a$ problem, something you don't un- derstand about it, they don't take time out to explain it to you.

Participant $\mathrm{J}$ based her assessment of the system as uncaring on the worker's behaviors. Her son had been in state custody for more than a year, but the worker visited the family only twice. Although parents tried to recognize that the system was overburdened, when workers did not take time for them, they interpreted their inattention as disrespect and apathy.

Participant $C$ said that the system treated her like a statistic and that she was "doomed from the beginning." She prescribed the need for focus on clients' strengths:

I think anytime you start out in the beginning and the person is a statistic, you have a burnt-out social worker. Because for one, I mean you don't even know me. You know nothing about me. All you know is, boom, I'm addicted and I've been addicted for what, 10 years. That's all she knew.

Parents believed the system did not care about them because promises were ignored or abandoned. One parent referred to this as "a lot of miscommunications." Participant $G$ said she was told if she completed certain tasks, then certain things would happen. But when she did her part, "the social worker reneged on her promises."

Unrealistic expectations. Parents wanted their children returned home. They described working through extremely long case plans that mandated them to participate in various services. They consistently said the system did not understand how much was asked of them and did not give credit for their accomplishments. Participant $B$ explained the logistics of participating in AA meetings.

\section{See, they don't know what it's like. They tell people to go to the meet ings, but they don't provide trans- portation or chlld care. I say, "What about my kids? Who's going to watch them?" They need to look at all that, you know. But they don't. They think you can do it and if she really wants them back she will do it. But H's hard, It's real hard.}

Many clients felt overwhelmed by agency expectations. The longterm goals of workers were often daunting for women who had spent so many years in a day-today existence.

\section{System Success}

Participants were eager to express their views about what helps families with addiction problems. The process of assuming the ex- 
pert role appeared to be a powerful experience for most parents. It was also a task that they took very seriously.

Though negotiating the child welfare system was portrayed as a difficult experience, participants gave credit to social workers who supported them during their recovery process. Indeed, these successful women perceived workers as truly making a difference in their lives. In response to a question about how they would describe their relationship with their social worker, participants said she is my "right hand," "friend," "guardian friend," "soul mate," and "like my family." The following themes were identified as key components in helping addicted families.

Trust. The prerequisite of a helping relationship is trust. Parents said they tested the social worker to find out "where she's coming from" and to determine if they could trust her. Many of them related life experiences that had instructed them to distrust all social workers. Trust grew out of workers' honesty, sincerity, and careful listening. Participant $\mathrm{C}$ said:

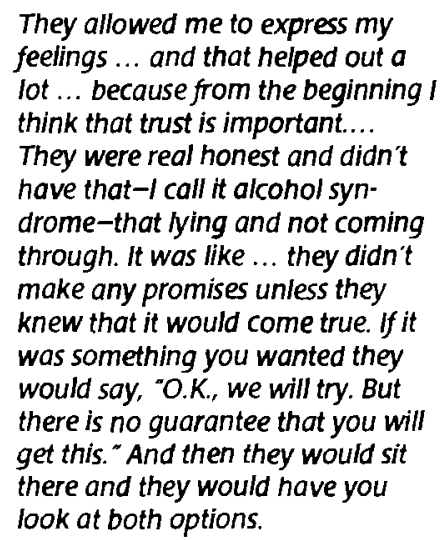

In order to build trust, participant $\mathrm{H}$ believed the worker must show concern for both parent and

child. The worker needed to listen to the parent before asking her to complete tasks.

\begin{abstract}
Listen to them.... When we are addicts and alcoholics and we are on that cocaine, we don't hear anything! But we have it inside of us. We have so much to tell... Have one ear, even if you don't understand what we are saying, have one ear. Listen to us. That makes us feel good, like somebody cares.
\end{abstract}

Availability. When discussing what works, parents depicted a social worker who called and visited frequently, listened intently, and was persistent in his or her efforts to help. They believed the social worker understood them and cared about them when he or she listened to their stories, "stayed on top of things," and carried a "sense of urgency." Participant E explained:

She know how to talk to you. She know where you comin' from. Don't matter what it is, she is there for you. At times I was wantin' to give up and I hung in there 'cause of her. I takes my frustrations out on [the social worker] and she sits there and takes it. She don't argue with me. She lets me get it off my chest. She talk to me and makes me think.

Caring. Effective social workers demonstrated to the family that they were interested in them and genuinely cared about them. Parents said that social workers "don't need to be a hard-ass." Rather, social workers should concentrate on expressing concern and caring. Participant D said:

Be human. Care. Get involved, not just you do this and you do that... Have a heart and care. Because, otherwise, that's probably why nine times out of ten, these people aren't gettin' sober and going straight. Because they just think that the system is goin' after them, just to make your world miserable.
Participant F said, "If you're social workers, then be social."

Faith. Parents explained that one thing that helped them change their lives was that their social worker did not quit believing in them. They attributed much credit to social workers who had faith that, despite their addiction, parents had the capacity to change. These workers were patient and kept believing in their

\section{«P arents attributed much}

credit to social workers who had faith that. despite their addiction. parents had the capacity to change."

clients' potential even when parents continued to battle with their addiction. Not even relapse dissuaded these workers. Participant $\mathrm{K}$ said, "It makes me feel really important because he has seen me at my worst and he did keep the faith. He saw the possibility for me." Instead of focusing on mistakes and problems, workers found a way to focus on the strengths in these women. As participant $\mathrm{H}$ said, "Social workers should have the patience and the support and have faith in your client! If you don't feel your faith is good enough, help her get somewhere where she can get that faith and that hope."

Sharing power. Trapped in a cycle of powerlessness in their relationships with drugs and the re- 
sponse of the helping system, parents needed to find their personal power. Workers contributed to this power by providing clients with choices and decision-making authority. Decision making helped parents feel as though they had control over their lives. Social workers who presented parents with choices demonstrated they believed the parent, not the social worker, knew what was best for the parent.

Participant J spoke about the importance of choices:

You can't make me do what you want me to do, and that's what they started dolng. Telling me, like I was a child or something, that I got to do this. No, I don't have to do anything. I do what I want because I am grown.

Social workers who shared authority and expertise with clients were finding ways for clients to experience power in the helping relationship. Participant $F$ explained that she felt special and important when her social worker consulted with her about working with another family who had problems with alcohol and drugs. The social worker treated this parent as an expert on addiction. As a result, participant $F$ recognized herself as knowledgeable and resourceful.

Workers provided parents with expanded choice and power by engaging parents in setting the helping agenda, by nurturing their selfesteem and sense of efficacy, and by helping them with concrete services such as housing, transportation, employment, and child care. Social workers assisted through advocacy and brokering.

Providing direction. Parents emphasized goal setting as an important worker activity. Participant

C explained that goal setting is important because it provides direction for addictive parents who get "lost in the middle":

\begin{abstract}
So the sodal worker has to pick them up in the middle. And if they can, kind of pick them up and direct them, like we were directed. Not carry them, but direct them to $B$. Then you be like, Wow!" Then maybe you can try to make it to $C$ But if they are lost in the middle and people are just squirrelin' them around, there's no chance... I'm talking in examples, but you really need to take it serious. You really need to take it serious 'cause they don't want to get lost. I belleve a lot of 'em do want to overcome, but it is just that fear.
\end{abstract}

Participant $F$ further explained that goal setting helps clients partialize their case plan tasks:

Say, O.K., this is your first step.
These will be your next two steps.
Don't make the list too long 'cause
that scene is ovenwhelming. All that
big log stuff and letting them see
this is going to take two years be-
fore you are actually anywhere in
life, that's too ovenwhelming. Drug
addicts are used to night now, night
now. So I believe that that would
work. It would have for me. To say,
O.K., we are just gonna do this little
bit at a time and let 'em know.

Years of living from one moment to the next leave persons with addiction problems unprepared to conceive of long-term goals and the behavior required for goal attainment. Although the road to recovery may be obvious to workers, their clients rarely grasp the way early in recovery.

Know addiction. Parents wanted workers to understand addiction, recovery, and relapse. They wanted practitioners to understand that relapse is not total failure but is often part of the recovery process. Participant J said she was afraid that if she were to relapse the worker would overreact:

If I relapse one time, you coming to get my child without even learning what the process is of being an addicted and akchollc mother... That can't keep happening... They can't keep snatching them babies from these mothers.

Parents want the social worker to understand their addiction and the process of recovery. They want the worker to empathize with their addiction experience, the difficulty of quitting, and the energy and persistence it takes to revamp one's entire life. In addition, parents want to be recognized as a unique individual with a particular experience to addiction. Participant A stated,

\section{I think the main thing is to realize that they're people. Recognize them as an individual, not a case... I'm a mother and a human belng first. Reallze each case is different, that there is reasons and that they can help them deal with it.}

Participant $\mathrm{H}$ also mentioned the importance of recognizing the person as a mother, not just as an addict.
Most women that are addicts and do drugs love their kids and love their bables. And the system needs to understand that because they down them women so bad. Be- cause they think because they do drugs, they don't love their kids.

\section{Implications for Social Work}

Though parents of this qualitative study were labeled successful, they clearly faced their share of struggle and distress. Often, parents depicted a system that was not user 
friendly. At the same time, they told stories in which a positive workerclient relationship made a difference in their lives. Drawing on the opinions of parents who have been successful in a complex, difficult system, this study provided insights into how to improve practice. Practitioners, administrators, policymakers, and educators can learn from these clients' experiences.

\section{Practice Implications}

Important information can be gleaned from parents' thoughts about the worker-client relationship. Many clients' comments reflect good social work practice. The infrequency with which these parents encountered such practice suggests the following key implications for practice.

The worker-client relationship. As in previous studies, parents in this study emphasized the importance of the helping relationship (Magura, 1982; Maluccio, 1979a, 1979b; Rubenstein \& Bloch, 1978). Magura (1982) identified four relationship qualities that clients gave as reasons for their satisfaction with the social worker: empathy, genuineness, unconditional positive regard, and accessibility. This study confirms the importance of these factors. However, parents in this study placed considerable weight on respect for the dignity and uniqueness of individuals (Compton \& Galaway, 1989). Parents' suggestions for workers can be summarized as follows:

- Be open and honest with clients in delineating mutual expectations.

- Use language that clients can understand.

- Demonstrate support and care through behaviors. Actions speak to these clients louder than words.
Help clients get the resources they need, such as housing, child care, and transportation. These activities were important in demonstrating that the worker cared for both children and parents.

a Listen to parents' stories, opinions, and aspirations. From these narratives emerged the resources clients used to survive as well as clues about their hopes for the future. Knowing clients' hopes and dreams directs the helping process toward goals that are important to them.

- Maintain a hopeful and nonjudgmental attitude. Parents want to know the worker believes in their ability to change their lives. Workers can instill hope by not judging the parent, by providing praise and positive feedback for small victories, and by being patient during times of slow progress.

- Share power and provide clients with choices. Parents feel they are in control of their lives when they are allowed to participate actively in decision-making.

- Help clients set incremental goals. When clients are full participants in the goal-setting process, they are more vested in the work required for making significant changes in their lives.

- Find ways to understand the nature of addiction and to know the parent as a unique individual. Workers can learn about addiction by visiting centers and attending open 12-step meetings.

Parents emphasize that having an addiction is not equivalent to not loving their children. Clients advise workers to consider the person rather than the case. Furthermore, parents instruct workers to express compassion and understanding for them. And perhaps most important, workers must be- lieve in their clients. By sharing a genuine sense of hopefulness, social workers have many opportunities to help parents overcome fear and powerlessness and to move toward individual action and change.

Use of power. This study suggests that social workers must be cognizant that the use of power can either impede or enhance helping (Diorio, 1992; Hartmann, 1993; Hasenfeld, 1987; Pinderhughes, 1983, 1989, 1994). Parents were immobilized by feelings of power-

\section{'Knowing clients' hopes and dreams directs the helping process toward goals that are important to them."}

lessness and hopelessness. They believed it was important for workers to provide parents with options and to show that they care and have faith in the client's ability to learn and grow.

If social workers are in the business of empowering clients, they should intervene in ways that give clients control and decisionmaking power. Social workers must be aware of ways in which the helping context places clients in powerless positions. Furthermore, when their children are removed from the home, parents clearly feel fear and helplessness. Perhaps more important than verbally addressing these issues with clients, workers must behave in ways that help clients feel more powerful. An example was provid- 
ed by a parent who felt important when her social worker asked her opinion about working with another family with addiction problems. This question transformed the parent into an expert. Situations that allow clients to assume positions of authority, to have choice, and to be viewed as having expertise create a helping environment in which clients realize their own power and potential.

Placing emphasis on increasing personal power, knowing the person independently of the addiction, and trusting the client's capacity to change represent a strengths approach to practice (Maluccio, 1979a, 1979b; Saleebey, 1992). If clients must have a social worker intrude in their life, then they want someone who cares about them and recognizes them as an individual with hopes and aspirations. They want social workers who believe in their potential for change, not workers who emphasize clients' mistakes and deficits. They want to be treated as adults who have the capacity to make decisions and determine their own life path. Parents do not want someone who does for them. They want someone who will provide support and direction and who will collaborate with them as they journey toward a healthier life.

\section{Social-Pollcy Implications}

A collaborative, comprehensive approach to family services is needed (Tracy, 1994). This study suggests that families with addiction often need ongoing support and comprehensive services. Brief intervention would not have been enough to help any of these clients overcome their problems with addiction. Additionally, parents need services that reach beyond conventional substance-abuse-treatment programs and child welfare interventions, including financial assistance, adequate and affordable housing, employment, and child care. Services should also include counseling and groups to help parents understand the meaning of their addiction and assist them in discovering new skills to achieve life goals.

Participants consistently reported frustration with workers who did not understand addiction. In each case, the client's journey toward recovery began only when she connected with a worker who was knowledgeable about addiction and willing to work with this population. Many social work curriculums provide only cursory instruction on addiction. Administrators must ensure that their staff receive adequate continuing education on addiction. Given the importance of knowledgeable and willing workers, administrators may also wish to explore the creation of specialist positions to be held by workers trained and assigned to work primarily with addiction.

Finally, programs serving this client population must manage relapse appropriately. Relapse does not indicate failure and it certainly is not an indication of lack of interest in one's children. Rather, it is the nature of addiction-a chronic, lifelong condition that implies the need for permanent support on an ongoing basis (Child Welfare League of America, 1992). Our policies and programs, then, must be proactive in responding to substance-abuse problems by recognizing the family's need for an array of services that offer long-term, intermittent support.

\section{Umitations}

In addition to including only 11 women, the sample presented here may have been limited by our definition of success. This definition includes participants' current abstinence and either completed or pending reunification with their children. Although the traditional definition of success is abstinence, some authors have suggested that this definition is too restrictive and recommend other indicators, for example, employment and relationship stability (Wolk, Hartmann, \& Sullivan, 1994). Defining success to include persons who returned to use without subsequent problems or those who relinquished their children may have resulted in different descriptions of the road to success. Our definition of successful parents meant that persons who still struggle with their addictions were rendered silent, though their input might be very instructive. The voices of fathers were also absent.

This study explored parents' perceptions of services and not necessarily outcomes of service. Future studies might focus on how social workers and clients know when they have achieved success and determine what outcomes are most beneficial to families. Such research can help identify characteristics of successful clients and workers as well as client outcomes that indicate success.

\section{Conclusion}

Attaining clients' perspectives of services is an essential component of social work (Giordano, 1977). An extensive literature review revealed that few studies of 
child welfare services use parents' views to evaluate services or to explore the impact that this encounter has on the family. In particular, parents with substanceabuse problems have not been targeted as a group who should be listened to. Parents with addiction problems have long been thought to be the most difficult or "hardto-reach" clients (Googins, 1984; Jenkins \& Norman, 1975; Kagle, 1987). This study confirms that even clients who are identified as hard to reach have meaningful contributions to make in evaluating services.

Parents' views provided several important considerations for social work. Parents described the power of addiction, the self-blame that surrounds it, and the conflict parents experience when trying to quit. Families need social workers who are knowledgeable about addiction and who do not condemn them. Parents also described the anger, loss, and sense of powerlessness they felt in their interactions with the system. As they worked their way through the system, they perceived a lack of support, caring, and respect. Additionally, parents felt the system did not believe in their capacity to change. Nor did the system comprehend the overwhelming amount of work it took to get their children out of state custody and back into their homes. Social workers need to understand and validate parents' feelings.

Parents related their success stories and what worked for them. They suggested a prescription for the worker-client relationship that reflected good social work practice. In general, clients wished to shift the focus from deficits to strengths. Though easy answers to these complex problems are not available, this study demonstrates three important points: (a) clients have valuable knowledge to share, (b) even people with addiction can get well, and (c) social workers can make a difference.

\section{References}

Besharov, D. J. (1990). Crack children in foster care: Re-examining the balance between children's rights and parents rights. Children Today, 19(4), 21-25.

Bogdan, R. C., \& Biklen, S. K. (1982). Qualitative research for education: An introduction to theory and methods. Boston: Allyn and Bacon.

Bratter, T. E, \& Forrest, K. E. (1985). Alcobolism and substance abuse: Strategies for clinical intervention. New York: Free Press.

Child Welfare League of America. (1992). Children at the front: $A$ different view of the war on alcohol and drugs. Washington, DC: Author.

Compton, B., \& Galaway, B. (1989). Social work processes. Belmont $\mathrm{CA}$ : Wadsworth Publishing.

Curtis, P. A., \& McCullough, C. (1993). The impact of alcohol and other drugs on the child welfare system. Child Welfare, 72, 533-542

Diorio, W. D. (1992). Parental perceptions of the authority of public child welfare workers. Families in Society, 73, 222-235.

Fanshel, D. (1975). Parental failure and consequences for children: The drugabusing mother whose children are in foster care. American Journal of Public Health, 65, 604-612.

Feig, L. (1990). Drug exposed infants and children: Service needs and policy questions, Washington, DC: U.S. Department of Health and Human Services.

Finkeistein, N. (1994). Treatment issues for alcohol-and drug-dependent pregnant and parenting women. Health and Social Work, 19(1), 7-14.

General Accounting Office. (1994). Foster care: Parental drug abuse has alarming impact on young children. Report to the chairman, Subcommittee on Human Resources, Committee on Ways and Means, House of Representatives. Washington, DC: U.S. Government Printing Office.

Giordano, P. C. (1977). The client's perspective in agency evaluation. Social Work, 22, 34-39.

Googins, B. (1984). Avoidance of the alcoholic client. Social Work, 29, 161-166.

Gregoire, T. K. (1994). Assessing the benefits and increasing the utility of addiction training for public child welfare workers: A pilot study. Child Welfare, 73, 69-81.

Gustavsson, N. S. (1991). Pregnant chemically dependent women: The new criminals. Affilia, 6(2), 61-73.

Hartmann, A. (1993). The professional is political. Social Work, 38, 365-366, 504.

Hasenfeld, Y. (1987). Power in social work practice. Social Service Review, 61, 469-483.

Jenkins, S., \& Norman E. (1975). Beyond placement: Mothers view foster care. New York: Columbia University Press.

Kagle, J. D. (1987). Secondary prevention of substance abuse. Social Work, 32, 446-448.

King, B. L., Bissell, L., \& O’Brien, P. (1979). Alcoholics Anonymous, alcoholism counseling, and social work treatment. Health and Social Work, 4, 181-198.

King, G., \& Lorenson, J. (1989). Alcoholism training for social workers. Social Casework, 70, 375-382.

Leake, G. J., \& King, A. S. (1977, Spring). Effect of counselor expectations on alcoholic recovery. Alcohol Health and Research World, 1, 16-22.

Lincoln, Y. S., \& Guba, E. G. (1985). Naturalistic inquiry. Newbury Park, CA: Sage Publications.

Magura, S. (1982). Clients view outcomes of child protective services. Social Casework, 63, 522-531.

Maluccio, A. N. (1979a). Learning from clients: Interpersonal helping as viewed by clients and social workers. New York: Free Press.

Maluccio, A. N. (1979b). Perspectives of social workers and clients on treatment outcome. Social Casework, 60, 394-401.

McCurdy, K., \& Daro, D. (1994). Current trends in child abuse reporting and fa- 
talities: The results of the 1993 annual fifty state survey. Chicago: National Committee to Prevent Child Abuse.

Morehouse, E. R. (1978). Treating the alcoholic on public assistance. Social Casework, 59, 36-41.

Peyton, S. (1980). Willingness to treat alcoholics: A study of graduate social work students. Journal of Studies on Alcohol, 41, 935-940.

Pilat, J. M., \& Jones, J. W. (1985). A comprehensive treatment program for children of alcoholics. In E. Freeman (Ed.), Social work practice with clients who have alcobol problems (pp. 141-159). Springfield, IL: Charles C Thomas.

Pinderhughes, E. B. (1983). Empowerment for our clients and for ourselves. Social Casework, 64, 331-338.

Pinderhughes, E. B. (1989). Understanding race, ethnicity, and power. New York: Free Press.

Pinderhughes, E. B. (1994). Empowerment as an intervention goal: Early ideas. In L. Gutierrez \& P. Nurius (Eds.), Education and research for empowerment practice. Monograph no. 7 for the
Center for Policy and Practice Research (pp. 17-30). Seattle, WA: School of Social Work, University of Washington.

Regan, D. O., Ehrlich, S. M., \& Finnegan, L. P. (1987). Infants of drug addicts: At risk for child abuse, neglect, and placement in foster care. Neurotoxicology and Teratology, 9, 315-319.

Reinharz, S. (1992). Feminist methods in social research. New York: Oxford University Press.

Rhodes, R., \& Johnson, A. D. (1994). Women and alcoholism: A psychosocial approach. Affilia, 9, 145-156.

Rubenstein, H., \& Bloch, M. H. (1978). Helping clients who are poor: Worker and client perceptions of problems, activities and outcomes. Social Service Review, 52, 69-84.

Saleebey, D. (Ed.). (1992). The strengths perspective in social work practice. New York: Longman.

Tatara, T. (1989-1990, Winter). Effects of the current drug epidemic on children: A critical need for national data. Protecting Children, 6(4), 15-23.

Thompson, L. (1990). Working with alco- holic families in a child welfare agency: The problem of underdiagnosis. Child Welfare, 69, 464-470.

Tracy, E. M. (1994). Maternal substance abuse: Protecting the child, preserving the family. Social Work, 39, 534-540.

Van Wormer, K. (1987, Spring-Summer). Training social work students for practice with substance abusers: An ecological approach. Journal of Social Work Education, 23(2), 47-56.

Walker, C., Zangrillo, P., \& Smith, J. (1991)). Parental drug abuse and African American children in foster care: Issues and study findings. Washington, DC: National Black Child Development Institute.

Wolk, J. L., Hartmann, D. J., \& Sullivan, W. P. (1994). Defining success: The politics of evaluation in alcohol and drug abuse treatment programs. Journal of Sociology and Social Welfare, 21(4), 133-145.

\section{COMING IN FAMILIES IN SOCIETY ... \\ A Special Focus on Foster and Kinship Care \\ family Functioning in Foster Care • Kinship Care and Foster Care • Foster Parents' attimudes \\ TOWARD BiRTH PARENTS AND CASEWORKERS • aND MORE ...}

These and other features, soon to appear in Families in Society, are designed to keep you informed and on top of your profession in this quickly changing and challenging world. Subscribe to Families in Society today and start receiving 6 full issues a year-plus the opportunity to earn CEUs for reading selected articles!

Individual rates: $\$ 45$ (one year), $\$ 84$ (two years), $\$ 117$ (three years). Institutional rates: $\$ 89$ (one year), $\$ 168$ (two years), $\$ 252$ (three years). Canadian subscribers add $\$ 6$ per year for postage; all other foreign subscribers add $\$ 21$ per year for air lift.

Families in Society, Subscription Dept., 11700 W. Lake Park Dr., Milwaukee, WI 53224

Enter my subscription for

Charge my $\sqsupset$ Visa

Signature

Name

Address

City/State/Zip year(s). Check is enclosed or

a MasterCard Acct. No.

Expiration Date 